\title{
Translocation of proteins into isolated chloroplasts requires cytosolic factors to obtain import competence
}

\author{
Karin Waegemann, Harald Paulsen and Jürgen Soll \\ Botanisches Institut der Universität München, Menzinger Str. 67, D-8000 München 19, FRG
}

Received 13 November 1989; revised version received 15 December 1989

\begin{abstract}
The precursor form of the major-harvesting chlorophyll $a / b$-binding protein (pLHCP) of chloroplast thylakoids was overproduced in $E$. coli cells and used to study the influence of soluble factors on post-translational protein import into isolated pea chloroplasts. pLHCP solubilised in $8 \mathrm{M}$ urea was not import-competent. However, if pLHCP was dialysed in the presence of soluble proteins (leaf extract) after urea treatment, import competence was gained. Dialysis of pLHCP in the presence of leaf extract alters its protease sensitivity. Stromal proteins, ovalbumin, trypsin inhibitor or chloroplast lipids could not produce import competence of pLHCP. Two components from leaf extract seem to be necessary, one of which can be mimicked by purified hsc 70 , the other one requiring ATP. We conclude that soluble proteins from outside the stromal compartment are necessary for post-translational import of proteins into chloroplasts.
\end{abstract}

Protein import; Chloroplast; Light-harvesting complex; Heat-shock protein, $70 \mathrm{kDa}$; Soluble factor; (Pisum sativum L.)

\section{INTRODUCTION}

Analysis of protein import into mitochondria has recently revealed that newly synthesized precursor proteins require cytosolic factors to adopt a conformation competent for transport [1,2]. Proteins participating in this process belong to the $70 \mathrm{kDa}$ heat-shock protein family $[3,4]$. In addition, an ATP-requiring process is involved to make precursor proteins competent for membrane translocation [5]. Studies of protein import into chloroplasts were hampered until now by the fact that the precursor proteins used in these studies were synthesized either in a wheat-germ or a reticulocyte lysate system [6], both of which have been shown to contain the complete set of proteins necessary to produce import competence of precursor proteins [5]. Consequently, it was impossible to assess the necessity or influence of soluble cytosolic plant proteins for posttranslational protein import into intact, isolated chloroplasts. We have overcome these obstructions by using the precursor form of the major chlorophyll $a / b$ binding protein of thylakoids in a highly purified state, free from cytosolic components. The present study shows that pLHCP translocation in chloroplasts is completely dependent on soluble proteins from leaf extracts (LE).

Correspondence address: J. Soll, Botanisches Institut der Universität München, Menzinger Str. 67, D-8000 München 19, FRG

Abbreviations: LE, leaf extract; hsc 70, heat-shock protein $70 \mathrm{kDa}$; pLHCP, precursor form of light-harvesting chlorophyll $a / b$-binding protein

\section{MATERIALS AND METHODS}

Isolation of chloroplasts from 7-9-day-old pea leaves was as in [7]. Chlorophyll was determined by the method described in [8]. The precursor form of LHCP was overexpressed in E. coli strain JM 101 transformed with a derivative of a pea $c a b$ gene cloned in plasmid pDS 12 [9]. pLHCP was labelled by the inclusion of ${ }^{35} \mathrm{SO}_{4}^{2-}$ in the bacterial growth medium. Purification of pLHCP was as in [9]. Protein was estimated as in [10] using bovine serum albumin as a standard. Leaf extract was isolated from 7-9-day-old leaves by homogenisation in a Perkin Elvejheim homogeniser. After centrifugation at $120000 \times g$ for $30 \mathrm{~min}$, soluble proteins were frozen in liquid $\mathrm{N}_{2}$ and stored at $-80^{\circ} \mathrm{C}$. Stromal proteins were isolated from Percollpurified chloroplasts [7] after hypertonic lysis in an identical manner as above. The purified pLHCP was solubilised in a small volume of $8 \mathrm{M}$ urea and centrifuged. An aliquot of the supernatant was diluted to $400 \mathrm{mM}$ urea prior to the dialysis by a buffer containing $50 \mathrm{mM}$

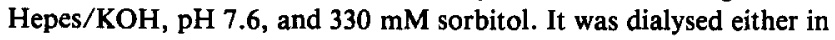
the absence or presence of soluble proteins from different sources on Millipore ' $V$ ' membrane filters (final vol. $50 \mu 1$ ). Dialysis was done for $30 \mathrm{~min}$ at $4^{\circ} \mathrm{C}$ against $30 \mathrm{ml}$ Hepes buffer (50 mM, pH 7.6), $330 \mathrm{mM}$ sorbitol. A standard import assay contained intact, purified chloroplasts (equivalent to $20 \mu \mathrm{g}$ chlorophyll), $50 \mathrm{mM}$ Hepes $/ \mathrm{KOH}$, pH 7.6, $330 \mathrm{mM}$ sorbitol, $3 \mathrm{mM} \mathrm{Mg}^{2+}, 2 \mathrm{mM}$ ATP, $2 \%$ BSA, $20 \mathrm{mM}$ $\mathrm{K}$-gluconate and $10 \mathrm{mM} \mathrm{NaHCO}_{3}$ in a final vol. of $100 \mu \mathrm{l}$. Transport was carried out at $25^{\circ} \mathrm{C}$ for $15 \mathrm{~min}$. Import was terminated by reisolation of intact chloroplasts through a $40 \%$ Percoll cushion followed by protease treatment (thermolysin $75 \mu \mathrm{g} / \mathrm{mg}$ chlorophyll, $10 \mathrm{~min}, 4^{\circ} \mathrm{C}$ ) [7]. Protease treatment was terminated by the addition of excess EDTA and repurification of intact chloroplasts through a Percoll cushion as above. Imported proteins were analysed by SDS-PAGE [11] and fluorography of the gels [12] as described in [7].

\section{RESULTS AND DISCUSSION}

Initial experiments showed that overproduced $\mathrm{pLHCP}$ denatured in $8 \mathrm{M}$ urea, that was used in import assays after rapid dilution of the urea did not become pLHCP import-competent in contrast to the behaviour 
of precursors in other import systems [13] (not shown). To become competent for membrane translocation, pLHCP had to be dialysed in the presence of LE. When LE was omitted or added after dialysis was completed, no LHCP import was observed (fig.1A). As demonstrated for protein transport into mitochondria and microsomes $[3,4]$, proteins of the $70 \mathrm{kDa}$ heat-shock family are part of the putative mechanism which 'unfolds' precursor proteins for translocation. In the case of chloroplasts, purified hsc 70 can only partially substitute for LE. ATP is without influence in the presence of purified hsc 70. However, if pLHCP is dialysed with leaf extract in the presence of ATP, the import efficiency is strongly enhanced, indicating a bipartite mechanism (fig. 1B). Hsc 70 is easily detectable in LE by Western blotting technique using an antibody described in [14] (not shown).

Increasing the LE concentration during dialysis resulted in increasing amounts of transported, protease-
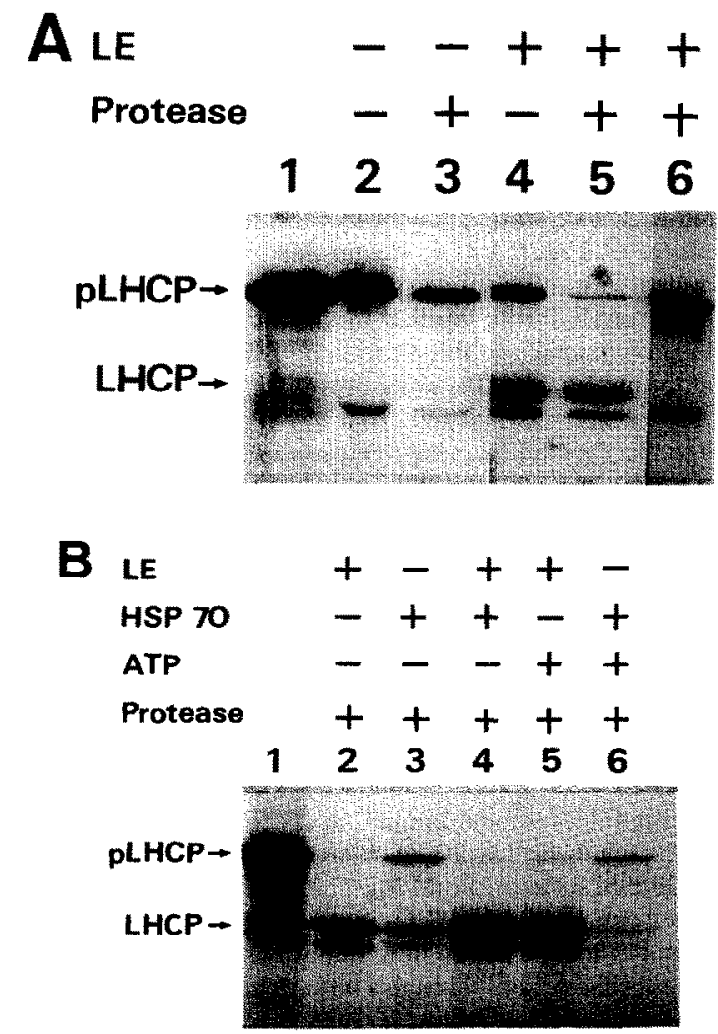

Fig. 1. Soluble leaf extract proteins are required for pLHCP import into pea chloroplasts. (A) Dialysis of purified pLHCP (lane 1) was carried out in the absence (lanes 2,3 ), in the presence of LE $(780 \mu \mathrm{g}$ protein; lanes 4,5), or LE was added after dialysis of pLHCP (lane 6). As indicated in the figure, chloroplasts were treated after import with protease. (B) Dialysis of pLHCP was carried out in the presence of different additions as shown on top of the figure: hsc $70(7.5 \mu \mathrm{g})$, ATP $(1 \mathrm{mM})$ during dialysis. The hsc 70 preparation contained $0.5 \mathrm{mM}$ ATP to give a concentration of $1.15 \mathrm{mM}$ ATP at the beginning of dialysis. Lane 1 in fig. $1 A$ and $B$, and 2 and 4 indicate the purity of the pLHCP used and do not correspond to the amount of precursor protein used in the transport assay. Products were analysed by SDS-PAGE fluorography. protected and processed LHCP in intact chloroplasts (fig.2, insert A). Transport efficiency is clearly saturable with respect to the amount of $\mathrm{LE}$ protein during dialysis (fig.2, line drawing), demonstrating the specificity of the import pathway. Interestingly, the chloroplast-bound precursor proteins exert a pronounced stability against thermolysin treatment at low LE concentrations (fig.2, insert A lanes 2-6). This was also observed in the absence of LE (fig.1A, lane 3) and in experiments where only exogenous hsc 70 was present (fig.1B, lanes 3,6), while higher LE concentrations make the precursor more susceptible to protease treatment. This could indicate that the 'unfolding' activity, which according to our results is most likely different from hsc 70, is the limiting activity in the extract under the conditions employed. pLHCP detected in these experiments would therefore represent a 'folded' form which is much more protease-resistant and can only be partially removed by thermolysin treatment. This notion is supported by our finding that $\mathrm{pLHCP}$ dialysed against saturating amounts of LE (cf. fig.2) is much more susceptible to trypsin treatment than pLHCP which was supplemented with LE just prior to trypsin treatment (fig.3). From the results shown in fig. 3 we conclude that the LE contains proteins which are able to associate with pLHCP and change the conformation of pLHCP (probably unfold it) so that it becomes more labile to protease treatment in vitro and more competent for import in situ.

Protein translocation-supporting activity is specifically present in LE (fig.4, lane 2) and cannot be mim-

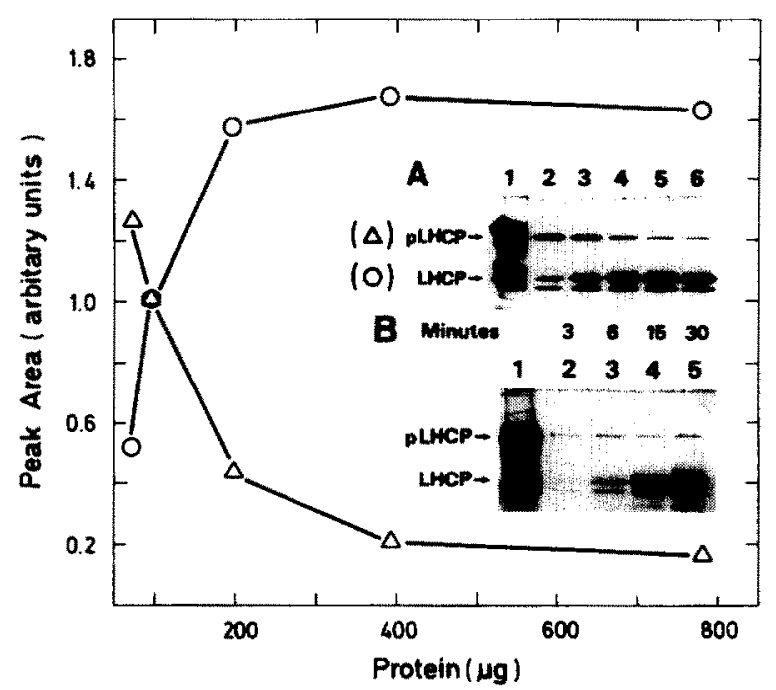

Fig.2. Import of pLHCP into chloroplasts depends on the amount of LE present during dialysis and the duration of the import experiment. pLHCP was dialysed in the presence of increasing amounts of $L E$ proteins for $30 \mathrm{~min}$ at $4^{\circ} \mathrm{C}$. Chloroplasts were treated with thermolysin after completion of import experiments. Insert A shows the fluorogram quantified for the line drawing. (Lane 1) precursor; (lanes 2-6) increasing amounts of LE as indicated in the abscissa of the figure. Insert B shows a time course experiment of pLHCP translocation after dialysis with $\mathrm{LE}$ ( $780 \mu \mathrm{g}$ protein). The fluorogram was quantified by densitometric analysis. 


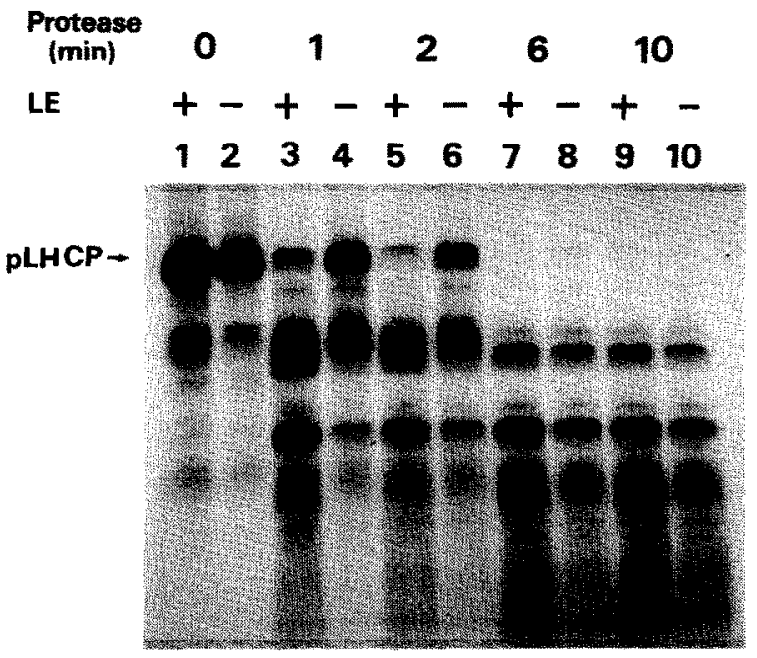

Fig.3. Dialysis of pLHCP in the presence of LE changes its trypsin sensitivity. pLHCP was dialysed in the presence (odd numbers) or absence (even numbers) of LE ( $780 \mu \mathrm{g}$ protein). Before trypsin treatment (130 units/mg protein) was started for the times indicated at $4^{\circ} \mathrm{C}$, an identical amount of LE proteins is added to the controls (even numbers). Products were analysed by SDS-PAGE and fluorography.

icked by other proteins present in the same concentration during dialysis. As demonstrated in fig. 4 (lanes 4 and 5), neither ovalbumin nor soybean trypsin inhibitor nor authentic chloroplast envelope membrane lipids (lane 6) could substitute for LE. Soluble proteins isolated from intact, purified chloroplasts exhibit only a low stimulating activity (fig.4, lane 3 ) indicating that most likely cytosolic proteins in the LE are responsible for pLHCP import. Soluble chloroplast proteins are mainly ( $>99.0 \%$ ) of stromal origin; further soluble proteins originate e.g. from the space between the two envelope membranes. They are very difficult to study and their influence on LHCP translocation could not be assessed in this work [15]. When pLHCP is dialysed in the absence of any other exogenous protein, no import is detectable (cf. fig.1, lane 3).

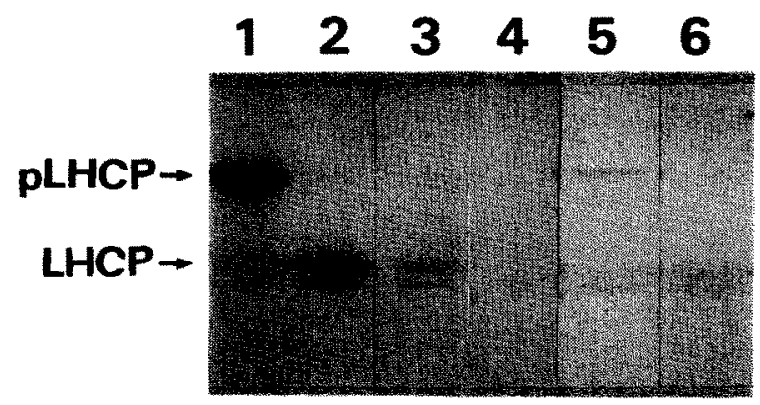

Fig.4. Conveying import competence to pLHCP is specific for LE. pLHCP was dialysed in the presence of equal amounts $(780 \mu \mathrm{g})$ of proteins from different sources: (lane 1) precursor; (lane 2) LE; (lane 3) soluble chloroplast proteins; (lane 4) ovalbumin; (lane 5) trypsin inhibitor; (lane 6) polar lipids isolated from $20 \mu \mathrm{g}$ mixed envelope membranes.
Soluble stromal proteins isolated from purified chloroplasts have been demonstrated to be required for the integration of pLHCP into isolated thylakoid membranes in vitro [16]. This stromal protein had a molecular mass of $65 \mathrm{kDa}$ and due to the described characterisstics could belong to the hsp 60 type of polypeptides which have been shown to act as molecular chaperones [17] and are required for the correct assembly into functional structures $[18,19]$. In summary, our results together with those in $[6,16]$ describe the pathway of a plant precursor protein destined for the chloroplast from its cytosolic origin to the translocation through the two envelope membranes, processing and final integration into the thylakoid membranes.

\section{CONCLUSIONS}

The present study extends our current knowledge on protein import into chloroplasts from the organellar level to the cytosolic site where the precursor proteins are synthesized. The data clearly demonstrate that soluble leaf proteins, most likely of cytosolic origin, are able to mediate translocation competence to pLHCP which by itself is not import-competent. The mechanism by which $\mathrm{pLHCP}$ is converted from a non-transportable into a transportable form seems to be at least bipartite, involving proteins of the hsc 70 family and an ATP. requiring polypeptide. Studies are underway to isolate the components of this system and to characterize this mechanism in detail.

Acknowledgements: We would like to thank Dr R. Zimmermann for the gift of purified hsc 70 and Dr L. Nover for the gift of hsp 70 antibodies. K.W. is supported by the Graduiertenförderung of the state of Bavaria. J.S. is recipient of a Heisenberg fellowship of the Deutsche Forschungsgemeinschaft. This work was supported by Sonderforschungsbereich 184.

\section{REFERENCES}

[1] Attardi, G. and Schatz, G.A. (1988) Rev. Cell Biol. 4, 289-333.

[2] Hartl, F.-U., Pfanner, N., Nicholson, D. and Neupert, W. (1989) Biochim. Biophys. Acta 988, 1-45.

[3] Deshaies, R.J., Koch, B.D., Werner-Washburne, M., Craig, E. and Schekmann, R. (1988) Nature 332, 800-805.

[4] Cirico, W.J., Waters, M.G. and Blobel, G. (1988) Nature 332, 805-810.

[5] Zimmermann, R., Sagstetter, M., Lewis, M.J. and Pelham, H.R.B. (1988) EMBO J. 7, 2875-2880.

[6] Keegstra, K., Olson, L.J. and Theg, S.M. (1989) Annu. Rev. Plant Physiol. Plant Mol. Biol. 40, 471-501.

[7] Schindler, C., Hracky, R. and Soll, J. (1987) Z. Naturforsch. 42c, 103-108.

[8] Arnon, D.J. (1949) Plant Physiol. 24, 1-15.

[9] Paulsen, H. and Rüdiger, W. (1989) in: Proceedings of the VIIIth International Congress on Photosynthesis (Baitscheffsky, M., ed.) in press, Kluwer Academic Publishers, Dordrecht.

[10] Lowry, O.H., Rosebrough, N.J., Farr, A.L. and Randall, R.J. (1951) J. Biol. Chem. 193, 265-275.

[11] Laemmli, U.K. (1970) Nature 227, 680-685.

[12] Bonner, W.M. and Laskey, R.A. (1974) Eur. J. Biochem. 46, 83-88. 
[13] Crooke, E. and Wickner, W. (1987) Proc. Natl. Acad. Sci. USA 84, 5216-5220.

[14] Neumann, D., zur Nieden, U., Manteuffel, R., Walter, G., Scharf, K.D. and Nover, L. (1987) Eur. J. Cell Biol. 43, 71-81.

[15] Soll, J. and Bennett, J. (1988) Eur. J. Biochem. 175, 301-307.

[16] Fulson, D.R. and Cline, K. (1988) Plant Physiol. 88, 1146-1153.
[17] Ellis, R.J. and Hemmingsen, S.M. (1989) Trends Biochem. Sci. 14, 339-342.

[18] Ostermann, J., Horwich, A.L., Neupert, W. and Hartl, F.U. (1989) Nature 341, 125-130.

[19] Ellis, R.J. and van der Vies, S.M. (1988) Photosynth. Res. 16, 101-115. 